www.nature.com/ejhg

\title{
BRCA2 founder mutation in Slovenian breast cancer families
}

\author{
Mateja Krajc ${ }^{2,3}$, Jacques De Grève*,1,3, Guido Goelen ${ }^{3}$ and Erik Teugels ${ }^{1,3}$
}

${ }^{1}$ Laboratory of Medical and Molecular Oncology, AZ-VUB (Free University of Brussels), Laarbeeklaan 101, 1090 Brussels, Belgium; ${ }^{2}$ Institute of Oncology, Zaloska 2, 1000 Ljubljana, Slovenia; ${ }^{3}$ Familial Cancer Clinic, AZ-VUB, Laarbeeklaan 101, 1090 Brussels, Belgium

\begin{abstract}
Linkage analysis has identified BRCA1 and BRCA2 germline mutations as the major cause for cancer predisposition in breast and/or ovarian cancer families. In previous screening efforts on Belgian families we had a BRCA1/2 gene mutation detection rate of $25 \%$. ${ }^{1}$ Here we report the results of a BRCA mutation screening in seven high-risk breast/ovarian cancer families from Slovenia. We found a single but highly recurrent BRCA2 splice site mutation (IVS16-2A $>G$ ) in three breast cancer-only families. This cancerlinked mutation could not be identified in three families with ovarian cancer, suggesting that the mutation predisposes at least predominantly to breast cancer. All mutation carriers shared a common disease associated haplotype indicating a founder effect. This mutation most probably occurred in a single ancestor and seems essentially confined to the Slovene population.
\end{abstract}

European Journal of Human Genetics (2002) 10, 879-882. doi:10.1038/sj.ejhg.5200886

Keywords: hereditary breast/ovarian cancer; BRCA2; founder mutation; Slovenia

\section{Introduction}

Five to $10 \%$ of all breast cancers are associated with an increased susceptibility resulting from a single autosomal dominant allele. The hereditary cause could be traced to the BRCA 1 or BRCA 2 gene in more than $80 \%$ of the large breast cancer families enrolled in research protocols. ${ }^{2}$ The cumulative risk for breast cancer for a woman carrying a BRCA $1 / 2$ mutation is estimated to be as high as $85 \%$ by the age of 70 years. The carriers are also at a substantially increased risk for ovarian cancer.

Since the identification of both genes and subsequent cloning more than 3700 cancer predisposing mutations have been reported to the Breast Cancer Information Core (Internet Website: (http://www.nhgri.nih.gov/Intramural_ research/Lab_transfer/Bic/)). These mutations are dispersed over the whole length of both genes and new mutations are still being added. Most mutations have been detected in a single or a few families at most. However, an increasing number of highly recurrent founder mutations have been

*Correspondence: Professor J De Grève, Medical Oncology - Oncologisch Centrum, AZ-VUB (Vrije Universiteit Brussel), Laarbeeklaan 101, 1090 Brussels, Belgium. Tel: +32 2 4776415; Fax: +32 2 4776210;

E-mail: jacques.degreve@az.vub.ac.be

Received 1 May 2002; revised 1 August 2002; accepted 6 August 2002 described in defined populations, such as the Ashkenazi Jewish, ${ }^{3}$ the Icelandic ${ }^{4}$ and the Dutch population. ${ }^{5}$

The current study pertains to the population residing in Slovenia. This Central European country has two million inhabitants with breast and ovarian cancer incidences of respectively 880 and 190 cases per year. ${ }^{7}$ Despite repeated occupations by foreign nations over several centuries, the inhabitants kept their unique language and cultural identity. BRCA1/2 mutation analysis had not been undertaken in Slovenia prior to this study.

\section{Methods}

Patients

The accrual started in October 1999, and probands were referred by general practitioners as well as specialists. The intake criteria for BRCA testing were: two or more firstdegree relatives with breast or ovarian cancer; if no ovarian cancer in the family, one breast cancer had to be diagnosed before the age of 50. All patients agreed to participate in the research study and provided written informed consent. The probands were seen at the Familial Cancer Clinic in Ljubljana. The initial efforts to disseminate the information about the availability of BRCA1/2 mutation testing and counselling among Slovenian physicians and patients resulted in 
the enrolment of seven families during a period of 20 months.

\section{Mutation screening}

Genomic DNA extracted from leukocytes of affected patients was used for the mutation analysis. Screening of exon 11 of the BRCA1 gene and exons 10 and 11 of the BRCA2 gene was done by Protein Truncation Test (PTT) as described by Hogervorst et al. ${ }^{7}$ The remaining smaller exons of the BRCA1 and BRCA2 genes as well as the $5^{\prime}$ and $3^{\prime}$ extremities of the large exons were analysed using the fluorescence - based conformation - sensitive gel electrophoresis (F-CSGE) method as described by Ganguly et al. ${ }^{8}$ PCR fragments were run on an ALF express automatic sequencer from Pharmacia. Samples revealing abnormal peak profiles, suggestive for the presence of heteroduplexes were further sequenced (Sequenase Version 2.0 DNA sequencing kit from USB).

A fast PCR-based assay aimed to detect the recurrent IVS16-2A $>$ G mutation was set up using a modified forward primer that creates a restriction site for Dde1 in the wild type but not the mutant PCR fragments (Fw: ATGATAATATTCTACTTTTATTTGCTC, Rv: CCTTCTGGGCTTAGGCATC). After enzymatic restriction, DNA from control patients produces a single $117 \mathrm{bp}$ long band after agarose gel electrophoresis (both alleles are cut) while DNA from mutation carriers generates an additional $141 \mathrm{bp}$ long band (wt allele cut, mutated allele not cut).

Splicing errors, expected to occur in mutation carriers, were confirmed by sequence analysis performed on RNA material isolated from leukocytes using the QIAamp RNA Blood Mini Kit from Qiagen (Cat No 52303).

In order to investigate whether the isolated recurrent mutation was a founder mutation, blood samples obtained from different members of the families harbouring the mutation were analysed using four polymorphic markers (D13S310, D13S1695, D13S1698, D13S171). ${ }^{9}$

\section{Results and discussion}

The probability of finding a germline BRCA1 or BRCA2 gene mutation in a breast cancer family depends on several factors. The most critical parameter appears to be the occurrence of ovarian cancer within the family. ${ }^{10}$ Also important may be the population under investigation. Several examples have been reported of restricted population groups harboring one or more highly recurrent founder mutations. ${ }^{3-5}$ This entails the possibility of low mutation detection rates caused by founder mutations that are not covered by classical routine screening methods.

Seven Slovenian families, suspected to be hereditary breast and/or ovarian cancer families, were enrolled in the BRCA1/2 mutation screen (Table 1). Based on the selection criteria and prior experience, ${ }^{1}$ we expected to isolate two to three mutations, most probably among the three families with ovarian cancer. Surprisingly, the PTT, which is able to identify the majority of the cancer predisposing mutations isolated in Belgian families, ${ }^{1}$ did not reveal any mutation among the Slovenian patients. When expanding the analysis to the remaining small exons by means of the F-CSGE method, abnormal peak profiles suggestive for the presence of heteroduplex DNA molecules were observed for five PCR fragments, but subsequent sequencing analysis revealed each time the presence of a polymorphism previously reported in the BIC database (IVS7-34C $>\mathrm{T}$ in BRCA1 and 203A $>$ G, IVS8+56C $>$ T, IVS14+53C $>$ T, IVS16$14 \mathrm{~T}>\mathrm{C}$ in BRCA2). However, in the fragment covering exon 17 of BRCA2, we found a putative splice site mutation (IVS16-2A $>$ G, Figure 1) in addition to the polymorphism. Since the presence of a common polymorphism in a particular PCR fragment may complicate the interpretation of results obtained by F-CSGE analysis, ${ }^{11}$ direct sequence analysis of the exon 17 region from BRCA2 was performed on all seven patients. To our surprise, the same IVS16$2 \mathrm{~A}>\mathrm{G}$ mutation was detected in two other families in which no heteroduplexes were found with the F-CGSE method. Repeating the experiment on more samples revealed that there was no correlation between genotype and peak profile, thus demonstrating the lack of sensitivity and reproducibility of the F-CGSE method for the fragment covering exon 17. In order to set up a fast and reproducible screening method for this particular mutation, we designed a PCR/Restriction-based approach (see Methods, results not shown).

We could also show that the first 20 nucleotides from exon 17 are missing in mRNA encoded by the mutant

Table 1 Characteristics of the Slovenian families screened for the presence of a BRCA1/2 gene mutation

\begin{tabular}{|c|c|c|c|c|c|c|c|}
\hline Family & 1 & 2 & 3 & 4 & 5 & 6 & 7 \\
\hline Number of breast cancers & 4 & 6 & 7 & 1 & 4 & 2 & 3 \\
\hline Ages at diagnosis & $45-47-65-73$ & NA & $43-44-50-50-60-60-61$ & 44 & $43-44-63-71$ & $28-42$ & $36-51-60$ \\
\hline Number of ovarian cancers & 0 & 0 & 3 & 1 & 1 & 0 & 0 \\
\hline Ages at diagnosis & - & - & $45-60-N A$ & 79 & 46 & - & - \\
\hline Breast and ovarian cancer in single individuals & 0 & 0 & 3 & 0 & 0 & 0 & 0 \\
\hline Bilateral breast cancer & 1 & 0 & 0 & 0 & 0 & 0 & 0 \\
\hline Number of other malignancies in the family & $\begin{array}{l}1 \text { testicular } \\
\text { cancer }\end{array}$ & 0 & 0 & $\begin{array}{l}1 \text { colorectal } \\
\text { cancer }\end{array}$ & 0 & 0 & $\begin{array}{l}1 \text { lung } \\
\text { cancer }\end{array}$ \\
\hline
\end{tabular}

$\mathrm{NA}=$ no data available. 
a. Genomic DNA

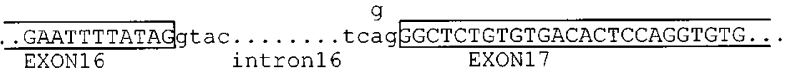

EXON16 EXON17

b. Wild type mRNA

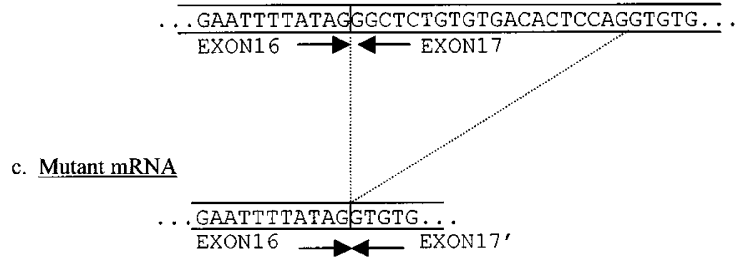

Figure 1 (a) A heterozygous BRCA2 splice site mutation (IVS16-2A > G) was identified in three out of seven families. Normal messenger molecules (b) as well as molecules missing the first 20 nucleotides of exon 17 (c) were found in the lymphocytes of mutation carriers, indicating that an alternative splice site located 20 nucleotides within exon 17 was used during transcript maturation. If translated, such mRNA molecules will produce truncated proteins.

BRCA2 allele as a result of the use of a cryptic splice site located within exon 17 (Figure 1). Such an alternatively spliced transcript was not encountered in the eight control samples tested.

Interestingly, this recurrent mutation was found exclusively in breast cancer-only families, in agreement with observations reported by Gayther et al. ${ }^{12}$ The investigation of a larger number of families carrying the IVS16-2A $>$ G mutation will reveal further to what extent this mutation specifically predisposes for breast cancer. This type of information will be relevant for discussing preventive options with patients carrying this particular mutation. The availability of this highly recurrent mutation may also contribute to the elucidation of the molecular mechanisms responsible for the tissue specificity of particular cancer-linked mutations. The IVS16-2A $>$ G mutation was reported worldwide only three times by the BIC database, twice by Myriad in 'Western Europeans' and once by Dr M Santarosa ${ }^{13}$ from Aviano, a city located in Italy at less than $100 \mathrm{~km}$ from the Slovenian border. The eastern part of today's Italy and Slovenia were before the First World War part of the Austro-Hungarian empire, and there is still a Slovene minority officially recognized in the eastern part of Italy. Since the Slovenian population stems from a common ethnic origin with a unique culture and language, the isolated mutation most probably occurred and propagated almost exclusively within this population group. The founder effect hypothesis could be confirmed by using a set of polymorphic markers flanking the BRCA2 gene (Table 2). A quite similar situation was, for instance, reported within the Dutch population where two founder mutations in BRCA1 are present in $36 \%$ of the Dutch BRCA1 families. ${ }^{5}$ None of
Table 2 Results of the haplotype analysis performed on one cancer patient from each of the seven families using five different STR markers flanking the BRCA2 locus

\begin{tabular}{lccccc}
\hline Family & IVS16-2A $>G$ & $D 13 S 310$ & $D 13 S 1695$ & $D 13 S 171$ & D13S1697 \\
\hline 1 & no & $3 / 4$ & $5 / 6$ & $1 / 6$ & $3 / 4$ \\
2 & yes & $1 / 4$ & $1 / 9$ & $1 / 1$ & $1 / 3$ \\
3 & no & $1 / 1$ & $5 / 6$ & $1 / 6$ & $1 / 3$ \\
4 & no & $1 / 2$ & $1 / 6$ & $1 / 1$ & $1 / 9$ \\
5 & no & $2 / 4$ & $5 / 8$ & $1 / 1$ & $3 / 4$ \\
6 & yes & $3 / 4$ & $6 / 9$ & $1 / 1$ & $3 / 3$ \\
7 & yes & $3 / 4$ & $6 / 9$ & $1 / 1$ & $3 / 9$ \\
\hline
\end{tabular}

Disease-associated haplotypes could be reconstructed for the three families carrying the mutation (results not shown). All three families were completely concordant for the 4-9-1-3 haplotype.

these two mutations could be identified in our Belgian families, indicating that families bearing a highly recurrent founder mutation can remain restricted to a very small geographic area.

Finally, absence of the IVS16-2A $>\mathrm{G}$ mutation in the three families that include an ovarian cancer patient strongly suggests that at least one other BRCA1 or BRCA2 mutation still remains to be identified in the study sample.

\section{Acknowledgements}

We thank Slovenian physicians and families for their cooperation. Goele Van Hassel and Kurt De Neef are acknowledged for their technical support. This work was supported by a grant from the 'Wetenschappelijk Fonds Willy Gepts' of the AZ-VUB.

\section{References}

1 Goelen G, Teugels E, Bonduelle M, Neyns B, De Grève J: High frequency of BRCA $1 / 2$ mutations in 42 Belgian families with a small number of symptomatic subjects. J Med Genet 1999; 36: 304-308.

2 Ford D, Easton DF, Stratton $\mathrm{M}$ et al: Genetic heterogeneity and penetrance analysis of the BRCA1 and BRCA2 genes in breast cancer families. Am J Hum Genet 1998; 62: 676-689.

3 Struewing JP, Abeliovich D, Peretz T et al: The carrier frequency of the BRCA1 185delAG mutation is approximately 1 percent in Ashkenazi Jewish individuals. Nat Genet 1995; 11: 198-200.

4 Thorlacius S, Olafsdottir G, Tryggvadottir L et al: A single BRCA2 mutation in male and female breast cancer families from Iceland with varied cancer phenotypes. Nat Genet 1996; 13: 117-119.

5 Petrij-Bosch A, Peelen T, Van Vliet M et al: BRCA1 genomic deletions are major founder mutations in Dutch breast cancer patients. Nat Genet 1997; 17: $341-345$.

6 Pompe-Kirn V, Zakotnik B, Benulic T, Volk N, Skrk J: Prezivetje bolnikov z rakom v Sloveniji. Ljubljana: Onkoloski institut, Register raka za Slovenijo, 1997 (Central Slovene Cancer Register, 1997).

7 Hogervorst FB, Cornelis RS, Bout M et al: Rapid detection of BRCA1 mutations by the protein truncation test. Nat Genet 1995; 10: 208 212.

8 Ganguly T, Dhulipala R, Godmilow L, Ganguly A: High throughput fluorescence-based conformation-sensitive gel electrophoresis (F-CSGE) identifies six unique BRCA2 mutations and an overall low incidence of BRCA2 mutations in high-risk BRCA1-negative breast cancer families. Hum Genet 1998; 102: 549-556. 
9 Neuhausen S, Godwin A, Gershoni R et al: Haplotype and phenotype analysis of nine recurrent BRCA- 2 mutations in 111 families: results of an international study. Am J Hum Genet 1998; 62: 1381 1388.

10 Gayther SA, Russel P, Harrington P, Antoniou AC, Easton DF, Ponder BA: The contribution of germline BRCA1 and BRCA2 mutations to familial ovarian cancer: no evidence for other ovarian cancer-susceptibility genes. Am J Hum Genet 1999; 65: 10211029.
11 Orban TI, Csokay B, Olah E: Sequence alterations can mask each other's presence during screening with SSCP or heteroduplex analysis: BRCA genes as examples. Biotechniques 2000; 29: 94-98.

12 Gayther SA, Mangion J, Russel P et al: Variation of risks of breast and ovarian cancer associated with different germline mutations of the BRCA2 gene. Nat Genet 1997; 15: 103-105.

13 Santarosa M, Dolcetti R, Magri M et al: BRCA1 and BRCA2 genes: role in hereditary breast and ovarian cancer in Italy. Int $J$ Cancer 1999; 83: 5-9. 